\title{
The Global Energy Transition: A Review of the Existing Literature
}

\author{
Manfred Hafner and Simone Tagliapietra
}

This chapter presents an overview of the existing literature on the geopolitics of the global energy transition. Notwithstanding its potentially re-defining role for international relations, this issue has, so far, not been analysed in a comprehensive manner but in a rather fragmented way. This chapter represents a useful summary to the state-of-the-art of knowledge in the field, and therefore a useful starting point for the book.

The first attempt to provide a holistic assessment of the geopolitics of the global energy transition has been made by IRENA (2019). This study maps the geopolitical transformations generated by the rise of renewables and the decline of fossil fuels. The study argues that the rise of renewables will reshape relations between states (i.e., oil and gas exporters versus oil and gas importers) and will lead to fundamental structural changes in economies and society. The report affirms that the world of the renewable energy transition will be very different from the one based on fossil fuels. The report claims that to some extent, the global energy transformation may generate a peace dividend, since the world is driving away from fossil fuels, which are often an aggravating factor in armed conflicts within states. However, the growth of digitalization in the energy sector due to the energy transition, can raise security and privacy risks in the absence of an international rules-based framework. IRENA affirms that global power structures and arrangements will change in many ways and the dynamics of relationships within states will also be transformed. Power will become more decentralized and diffused. Those countries that have invested in renewable technologies will increase their influence in the global context; while, by contrast, those states that rely heavily on revenues from fossil fuels will face substantial challenges to their economic and social models.

Following the IRENA report, Goldthau et al. (2019) published a first academic analysis outlining some geopolitical scenarios for the transition by 2030 . The authors present four different scenarios for the energy transition and its effects on global

M. Hafner (凶) S. Tagliapietra

Fondazione Eni Enrico Mattei (FEEM), Milan, Italy

e-mail: manfred.hafner@feem.it 
geopolitics. The first scenario ('Big green deal') assumes full cooperation due to a global consensus for action on climate change leads to a concerted international policy. In this scenario, a wave of green globalization allows all countries to share in the benefits of decarbonization; petrostates are compensated to transition smoothly to a sustainable economy. The result is a win-win for climate and security, geopolitical friction is low. The second scenario ('Technology breakthrough') assumes that a major technological advance steers the world along a different path. The US and China take the lead in scaling up the technology, but competition between nations also spikes. Indeed, the world fractures into two camps in a cleantech cold war, where technology leaders hold the power and others gravitate towards one of the leaders, reinforcing regional blocs and increasing rivalry. Fossil-fuel producers have to adapt rapidly to falling demand, with tensions rise in some areas. The third scenario ('Dirty nationalism') assumes that nation-first policies put a premium on self-sufficiency, favouring domestic energy sources over imported ones, which drive the development of fossil fuels as well as renewables. In this context, zero-sum logic returns and power rivalries marginalize the UN and undermine multilateral institutions. The fourth scenario ('Muddling on') is a business as usual one, resulting in a mix of energy clubs, with little cooperation. Fossil fuels remain dominant, despite renewables claim an increasing share of the energy mix by 2030, as unit costs keep declining. The speed of the energy transition is too slow to mitigate climate change, but too fast for the fossil-fuel industry to adapt. Oil-producing countries in the Middle East, Russia and Africa see political turmoil as government coffers empty. Motivated by energy security as much as climate change, countries pursue diverse energy strategies. As some regions have inadequate regulation or fail to benefit from these partnerships, existing economic and geopolitical imbalances are reinforced and energy inequality rises. The authors outline three steps that will help to put geopolitics at the heart of debates about the energy transition: (i) researchers and decision-makers need to shift the attention from targets to pathways; (ii) policymakers need to draw lessons from past and parallel experiences and (iii) abating carbon will create losers, thus now the policy focus needs to switch to the potential conflicts resulting from falling fossil-fuel demand, and the related economic and security risks.

Hafner and Wochner (2020) also provide an outlook of how the global energy transition will play out among the different major global geoeconomic/geopolitical blocks and how it may affect and be affected by global governance. They argue that four main unfolding drivers will lead to major tectonic shifts in the global energy system: i-global energy demand, spurred largely by Asia; ii-“"top-down" climate policies that contribute to decarbonization of the global economy; iii-bottom-up technology and market-driven digitalization that favour new energy approaches and also a more decentralized energy system; iv-technological innovation that drives the energy industry both in the fields of renewable energy and low-carbon vehicles, but also in unconventional oil and gas production. The authors then present the strategies presently being developed by the different major global countries/block and they argue for instance that Europe being a major energy importer has a much higher incentive to push for decarbonization policies which bring the co-benefit of 
improved energy security compared to the United States, which is presently experiencing an economic boom thanks to its unconventional oil\&gas revolution allowing it to not only to have access to cheap energy but to even become a major gas exporter and possibly a net oil exporter. At the same time, the US thanks to its formidable entrepreneurial spirit, China with its state-driven policies, but also Europe and Japan are investing heavily in developing new low-carbon technologies which should provide them with a technological and economic advantage in a decarbonizing world. Russia and hydrocarbon exporting Middle East countries, on the other hand, face challenges in the energy transformation of their economies due to multiple system inertia. The authors then test the strategies of the different major global blocks under three possible future scenarios: i-Weak Climate Governance; ii-Global Efforts for Climate Acton; iii-Muddling Through. They argue that with globally Weak Climate policies, energy-exporting countries (the Gulf States, Russia and the US) would remain in a strong position while Europe may end up paying a high price in the short term as its investments in low-carbon technologies may not pay off as quickly as planned, though the medium-long term will provide it with an increased independence from increasingly volatile global energy prices. In a Global Efforts for Climate Action scenario, those countries who are at the forefront of the energy transition will be the clear winners, these include Europe but also China and the US, while traditional fossil fuel producers and exporters (Gulf countries and Russia) will need to quickly diversify their economies if they want to continue to have a role on the international scene (they could for instance convert from fossil fuel exports to hydrogen exports). The authors conclude that the present weak global network spanning the energy field does not provide effective governance mechanisms. The most effective way to govern a global energy transition is to create increased ownership of climate policies both among countries (developed, emerging, developing) and inside societies (rich, middle-class and poor) thanks to a more inclusive and just redistribution of burdens (everybody needs to see a win-win solution for itself), and at the same time to strengthen the review mechanisms of the Paris Accord to oblige States to bring their national energy and climate strategies in line with the goal of preserving the planet Earth.

A comprehensive review of the existing literature on individual aspects of the geopolitics of the global energy transition is now presented, to provide the reader with a clear picture of the current status of knowledge in the field. To facilitate the reader, this literature review follows the structure of the book.

From a regional point of view, there is a heterogeneous spectrum about the quantity and quality of the existing literature: profusion on Europe and MENA, scant/meagre on Russia and the US, while there is almost no study on geopolitical analysis of the energy transition in Africa and China. 


\section{Europe}

Bressand (2012) affirmed that the world energy system is undergoing a far-reaching transition in which three agendas collide: an economic agenda of supply and demand and of national competitiveness; a security agenda reflecting strategic dependence on trade in oil and gas and a sustainability agenda now centred on the search for a low-carbon energy mix. The paper seeks to identify the key players and their strategic postures in this new era of energy geopolitics, with a view to drawing implications for the European Union and the US. The paper identifies the energy seven countries with the highest influence on energy and climate relations across energy sources. The author evaluates Saudi Arabia, Iraq, China and Japan as 'status quo' countries in terms of their core policy stance regarding the global energy system and markets. Then, he shows how the Russian Federation and the EU are the two players intent, for very different, reasons, on changing the game. However, the author affirms that the thrust of the conclusions regarding Europe is far less optimistic than is the case in prevailing views that tend to define success. Gains tend to be assessed with reference to the world as Europeans would like it to be rather than as it is. A geopolitical perspective and the less complacent cost-benefit analysis suggests lead to a sharper and more realistic assessment of energy and climate policy options.

Lombardi and Gruenig (2016) consider low-carbon energy security and energy geopolitics in Europe focusing on four thematic clusters: challenging the energy security paradigm; climate change and energy security objectives (the components of a secure and low-carbon energy system); energy security in a geopolitical perspective, as it relates to economics, resource competition, and availability; and the influence of large-scale renewable energy projects on energy security and shifting geopolitical alliances. The book is developed around three themes: energy security in a geopolitical perspective; reshaping equilibria: renewable energy mega-projects and distributed generation; developing policy strategies towards a low-carbon and secure energy system.

Eyl-Mazzega and Mathieu (2019) highlight that the geopolitical and geoeconomic issues related to energy and climate policies are becoming more complex. They affirmed that to the old and existing energy rivalries, there is the emergence of new rivalries related to the energy transition, especially regarding the control of the value chains of low-carbon technologies, which are crucial for competitiveness, economic development, energy sovereignty and security. In this race, China and the US have taken a certain lead. The authors pointed out that the EU has scientific and industrial strengths, but public policies have favoured the breaking up of industrial entities to foster competition and open markets in order to lower prices for consumers, sometimes at the cost of technological leadership objectives. The authors also outlined the necessary steps that the EU, France and Germany should take in order to benefit from the energy and technological transition. 


\section{United States}

Pascual (2015) provides a framework to understand the relationships between energy geopolitics and energy markets, with an underlying premise that neither energy markets nor foreign policy is static. The paper explained that America's new oil and natural gas abundance will not ultimately lead to a more isolated position in global energy markets, because it will not serve its national security interests within a global energy market. The author affirms that the US, like other major energy producers in the past, has used its newly tapped energy resources to support its international objectives. However, interfering with markets can come with unintended consequences that can ultimately undermine the interests of the US and its international partners. Pascual states that if stopping climate change remains a key foreign policy and national security concern, then the financial and technical factors driving these investment trends must become a priority at the intersection of energy markets and geopolitical interests.

\section{Russia}

Makarov et al. (2017) begin from the fact that Russian budget relies heavily on exports of fossil fuels and they assess the impacts of the §Paris Agreement on the Russian economy and find that climate-related actions outside of Russia lower Russia's GDP growth rate by about a half of a percentage point. Through a number of scenarios, the article shows how the future landscape post-Paris Agreement might affect the Russian economy, which is highly dependent on production and exports of fossil fuels. For Russia, it is critically important to get ready to mitigate the risks associated with the Paris Agreement by adjusting itself to the new energy landscape. They argue that the objective of Russian strategy should be broader than just planning low-carbon development. In addition to the plans to support low-carbon technologies that are most relevant to the Russian market and to introduce new regulations and legislative incentives promoting low-carbon development (including emissions disclosure requirements and a carbon pricing scheme), the strategy should find ways to address three types of risks: of reducing energy exports, of additional market barriers to Russian exporters of energy-intensive goods, and of relying on outdated energy technologies. In conclusion, the authors affirm that the post-Paris energy landscape poses a challenge for Russia and its energy and economic model. The current way of fossil export-based development will be difficult to sustain in the coming decades, regardless of Russia's own climate policy choices. 


\section{Mena}

Despite the MENA region is commonly linked with fossil fuels, only in the last years some studies have been made on the effects of the global energy transformation for the region. One of the most recent study is the one proposed by Goldthau and Westphal (2019), in which the authors challenge the assumption of the end of the petrostates due to the global energy transition. They affirm the global energy transition might even throw some petrostates an additional lifeline, for examples, those petrostates that have already started to move up the energy value chain by building up refining capacity and developing a viable petrochemical industry, namely, Saudi Arabia, the United Arab Emirates or Kuwait. The authors affirm that the global energy transformation does not mean the end of the petrostate. The low-carbon transition may in fact well facilitate new oligopolies, and a higher market concentration among fewer crude suppliers. They state that fast decarbonizers commitment to making the bright clean energy future work will therefore need to prepare for a twofold challenge: managing a rapidly changing energy system in order to secure the transformation dividends it will bring for human security and economic welfare and balancing the (geo) political order after pains of the incumbent fuels leaving the system.

Weatherby et al. (2018) published a report on UAE energy diplomacy and its role in exporting renewable energy to the global south. This analysis identifies three arenas, where the UAE can strategically expand its clean energy diplomacy in order to help mitigate carbon emissions in developing countries: capacity building, strategically targeted foreign aid and increased commercial ties in the renewable energy sector in developing countries. One of the main messages of the analysis is that there is an opportunity for the UAE to build its soft power and reap commercial benefits by helping countries throughout the Global South implement renewable energy projects. The authors affirm that the UAE can play a leading role in Southeast Asia's energy transition, which should be a priority target for UAE clean energy diplomacy.

Luomi (2018) frames the overall challenge for the UAE and other Gulf Arb ab energy exporters which, due to structural similarities, will be facing many of the same external challenges. The paper identifies three interests the UAE has vis-à-vis the transition: remaining a global energy supplier; ensuring that domestic energy targets can be met and ensuring economic prosperity through a diversified economy. She identifies the main economic challenges to the UAE in the context of the transition that is related to: maintaining or increasing oil exports at competitive prices long enough, while increasing the share of higher value oil-based exports to enable a stable transition in terms of government revenue and the broader economy; and meeting domestic energy demand growth without compromising on environmental sustainability. Finally, the author argues for the need for governments in the region to develop outward-oriented and comprehensive 'energy diplomacy strategies' that build on domestic energy agendas, address these opportunities and challenges and proactively engage with a world that is moving away from hydrocarbons.

Griffiths (2017) provides an assessment and outlook for energy policy in the MENA region within the context of the myriad factors impacting policy design and 
implementation. The author affirms that although the MENA region will continue to be a major oil and gas producer, consumer and exporter for years to come, a global transition to new sources of energy supply is underway and this will continue to impact all MENA countries. The assessment of the current MENA region context suggests that driving forces for the evolution of energy policy are energy security and energy cost minimization. Griffiths underlines that although renewable energy is a central topic of energy system diversification globally, there is significant interest regionally in nuclear energy and coal to complement greater use of natural gas in the power sector. Regional energy cooperation is essential but must be approached in a thoughtful and realistic manner, according to the author. In conclusion, he states that evolution and transition of the MENA energy system will be challenging but will progress out of necessity. Advances for now will mainly be based on transactional exploitation of easier opportunities.

Luomi (2015) examines how the resource-rich GCC countries are positioning themselves in the international relations of the green economy, focusing in particular on how the United Arab Emirates is seeking to acquire the means of implementation for a national green energy economy transition. She affirms that while not unique in a global perspective, the case of the UAE is unique in the GCC context: unlike its neighbours, the UAE has actively embraced the 'win-win' aspects of the green economy agenda, initiating numerous partnerships and programmes. The case study of the UAE provides important lessons for the other GCC states and to other resourcerich developing countries as well. She affirms that the case of the UAE shows how a benefits-oriented approach to the global governance of environmental problems has so far brought its benefits, through its participation in multiple international partnerships that provide invaluable political and technical support and foster new economic partnerships 'free to charge'. Another lesson is that successes of the UAE's sustainable energy drive have resulted from support at the highest levels of decisionmaking.

Tagliapietra (2019) illustrates the persistent over-reliance of MENA hydrocarbon producers on the hydrocarbon rent. His article presents the ambitious economic reform programmes adopted by MENA hydrocarbon producers since the drop-in oil prices began in 2014, suggesting a positive view on their implementation prospects. The author highlights that two additional arguments have emerged for economic diversification, besides the risk of oil market volatility: the uncertainty regarding the speed of the global energy transition, and the pressing need to create job opportunities for a large and youthful population. In conclusion, the global energy transition might then turn out to be a positive input for MENA hydrocarbons, a stimulus to consider economic diversification as an unavoidable pathway, to be pursued in order to guarantee future economic prosperity in any future scenario-even in a low-carbon world scenario.

We now provide a review of the existing literature related to the in-depth focuses developed in the second part of the book (i.e. the impacts of the transition on economic growth and income distribution, the role of the global South, the relevance of minerals and metals for low-carbon technologies as well as governance and financing of the global energy transition). 


\section{The Impacts of the Energy Transition on Economic Growth and Income Distribution}

IRENA (2016) published a report on the economic benefits generated by the renewable energy, providing the quantification of the macroeconomic impact of doubling the global share of renewables in the energy mix by 2030. The study demonstrates that the benefits of scaling up renewable energy surpass cost competitiveness. It claims that doubling the share of renewables in the global energy mix by 2030 would increase global GDP between 0.6 and $1.1 \%$ or between around US $\$ 700$ billion and US\$1.3 trillion. Additionally, according to IRENA's report doubling the share of renewables increases direct and indirect employment in the sector to 24.4 million by 2030. The report explains also the impacts on fuel importers and exporters generated by the increase of the renewable energy share in the global energy system.

Santos Pereira et al. (2019) propose a research, aiming to empirically assess and discuss: (i) whether different types of household have suffered dissimilar effects from the promotion of renewables; (ii) the consequences of promoting renewables on household income; and (iii) if the promotion of renewables has reduced the risk of poverty and social exclusion. The research found that the income of different households has differing effects on RES promotion, benefiting hydropower and solar PV. Secondly, the authors found that the installed capacities of both wind power and hydropower, and the overall share of RES have dissimilar impacts on different households, but they have increased the income of some. However, the unexpected finding was the negative effect of solar PV deployment on household income. Thirdly, the capacity of wind and hydropower have reduced the risk of poverty for some households, but have increased the risk for others.

Concerning the impacts of climate policies on households of different income levels, a relevant study was conducted by Zachmann et al. (2018). The authors present three different kinds of policy: (i) progressive, policies that make low-income households better off relative to high-income households; (ii) regressive, policies that have the opposite effect; and (iii) proportionate, policies that equally affect high- and lowincome households. They identify four factors why households with low incomes are affected differently by individual climate policies; the factors are: budget constraints that lead households with low incomes to prefer different consumption baskets; have higher discount rates/feature borrowing constraints that prevent them from procuring more efficient durables; have different skill endowments and hence wages; and, earn less income from capital and land. They find that key climate policy tools such as carbon taxes for different fuels, certain mandatory standards, subsidies and regulatory tools, can be regressive. They affirm that while several 'pure' climate policies can be regressive, the costs and impacts of climate change are also likely to fall disproportionately on low-income households. They suggest to invest more in research on the distributional effects of climate policies; improve policies and making them less regressive; develop climate policies that benefit low-income households, such as support for energy-efficiency investment targeted at low-income households. 
Islam and Winkel (2017) offer a unifying conceptual framework for understanding the relationship between climate change and social inequality. The authors affirm that available evidence indicates that this relationship is characterized by a vicious cycle, whereby initial inequality causes the disadvantaged groups to suffer disproportionately from the adverse effects of climate change, resulting in greater subsequent inequality. The paper identifies three main channels through which the inequalityaggravating effect of climate change materializes: (i) increase in the exposure of the disadvantaged groups to the adverse effects of climate change; (ii) increase in their susceptibility to damage caused by climate change and (iii) decrease in their ability to cope and recover from the damage suffered.

OECD (2017) argues that boosting economic growth, improving productivity and reducing inequalities need not come at the expense of locking the world into a highemissions future; stating that it is the quality of growth that matters. The report affirms that with a climate-compatible policy package, countries can increase long-run GDP by up $2.8 \%$ on average across the G20 in 2050. In order to foster a sustainable economic growth, investment in modern, smart and clean infrastructure in the next decade is a critical factor. The report estimates that $\$ 6.3$ trillion of investment in infrastructure is required annually on average between 2016 and 2030 to meet development needs globally. An additional \$0.6 trillion a year over the same period will make these investments climate compatible. Finally, the report affirms that finance and fiscal activities are essential in fostering a sustainable economic growth.

Hallegatte et al. (2016) published a report that emphasizes how climate change could set back poverty eradication efforts. The report underlines that the future is not set in stone; therefore, it affirms that there is a window of opportunity to achieve the poverty objectives in spite of climate change by pursuing both rapid, inclusive and climate-informed development, combined with targeted adaptation interventions, to cope with the short-term impacts of climate change and, secondly, immediate propoor mitigation policies to limit long-term impacts and create an environment that allows for global prosperity and the sustainable eradication of poverty.

Cludius (2015) analyses two energy and climate policy instruments, namely, renewable energy policy and the European Union Emissions Trading Scheme (EU ETS), in the context of the distribution of costs and benefits arising from these policies. The author shows that, contrary to public perception, the distributional outcomes are not an inherent feature of the energy or climate policy instrument at hand, but are largely determined by the way in which it is designed. Indeed, industry exemptions from contributing to the cost of both renewable energy policy and emissions trading have been generous and allowed for considerable profits to the companies covered by those schemes. This has led to a situation where households bear the majority of the direct costs associated with those policies. The analysis indicates that low-income households are particularly affected by the associated price increases, because they spend a large fraction of their income on electricity and other emissions-intensive goods. There is scope for governments to improve the situation of (low-income) households through three mechanisms: a reduction of price; household income via financial assistance to households; and energy efficiency measures needed to reduce household consumption of electricity. Finally, the author suggests that there is no 
basis for pitching climate against equity concerns, but rather there are many opportunities for policymakers to formulate an integrated approach that addresses both issues concurrently.

Dercon (2014) underlines that due to their initial poverty and their relatively high dependence on environmental capital for their livelihoods, the poor are likely to suffer most due to their low resources for mitigation and investment in adaptation. The paper focuses on three elements of green growth policies: pricing and regulation to internalize environmental capital costs; low-carbon and other environmentally sensitive public investments and 'green' adaptation and other resilience-enhancing investments. The report argues that green growth could potentially have important negative consequences for the poor that may even outweigh the benefits for the poor from growth. The author states that environmental pricing and regulation may have considerable negative consequences for the poor as consumers, and would require specific social protection measures to compensate for price rises. Therefore, the authors warn that promises that green growth will offer a rapid route out of poverty are not very plausible; there may well be less rapid an exit than with more conventional growth strategies.

Grösche and Schröder (2014) assess the redistributive effects of a key element of German climate policy, the promotion of renewables in the electricity generation mix through the provision of a feed-in tariff. The authors show that the tariff shapes the distribution of households' disposable incomes by charging a levy that is proportional to household electricity consumption and by transferring financial resources to households who are feeding green electricity into the public grid. The paper analyses the question whether the feed-in tariff scheme increases income inequality in the society and thereby conflicts with the general social goal to reduce disparities in peoples' disposable incomes. They state that the share of renewable fuels in the electricity generation mix increased under the regime of the feed-in tariff from $7 \%$ in 2000 to about $20 \%$ in 2011, but also imposed substantial cost to the electricity consumer by subsidizing renewables.

\section{The Global Energy Transition and the Global South}

Hirsch et al. (2017) provide an overview of the different just transition, energy transformation and climate justice discourses of the previous years and how they are ultimately reflected in the Paris Agreement. The authors show how these discourses overlap in terms of transition narratives and policy demands, and they affirm that the shared value base could serve as a starting point for building alliances, which are necessary to make just transition become a reality. The report outlines eight principles related to the just energy transition designed to make justice applicable to energy transition processes in developing countries, which go beyond an abstract call for justice. These principles cover the climate, socioeconomic and political dimensions in a balanced way to reflect the legitimate justice claims of a broad range of potential allies for a just energy transition alliance. These principles are then applied as a 
reference framework for 12 countries of the Global South (China, India, Vietnam, Philippines, Nepal, Fiji, Morocco, South Africa, Tanzania, Mexico, Costa Rica and Jamaica). The just energy transition country assessments have shown that neither are countries who internationally claim to be climate champions in terms of energy transition necessarily performing well in terms of the social and political dimension of a just transition, nor are those who claim to pioneer justice automatically in the lead in transforming their energy systems in a way that is consistent with a $1.5 / 2{ }^{\circ} \mathrm{C}$ pathway. The scoring indicates that country performance is generally strongest in terms of the climate and energy dimension of the transition, while countries are doing less well in terms of addressing the socioeconomic dimension of a just energy transition.

\section{The Geopolitics of Renewable Energy}

One of the most analysed topics related to the shift from geopolitics of oil and gas to geopolitics of renewable energy. The most relevant work is the book edited by Scholten (2018), which is the first volume to explore the geopolitical implications of a transition to renewable energy. The book tackles a wide variety of topics, namely, winners and losers of the new emerging global energy scenario, the change in regional and bilateral energy relations between established and rising powers and the governance responses to the transition as well as infrastructure developments. The authors affirm that the future geopolitical world of energy will be a mixed between the one of renewables and the one of conventional energy. It will be different because it will be a more decentralized system; it will be similar to the conventional energy because bigger projects in renewable suffer from very similar security issues, for example, where and who will control certain pivotal power lines. The book states that the geopolitics of conventional energy and that of renewable energy will exist next to each other for a period of several decades.

Overland (2019) addresses four emerging myths about the geopolitics of renewable energy, seeking to stop them developing further. The four emerging myths are: competition over critical materials; new resource curses; electricity disruption as a geopolitical weapon; cybersecurity as a geopolitical risk. Regarding the first myth, Overland affirms that energy transition is about mainly technology and innovation; therefore, she believes that it is highly probable that there will be technological improvements and cost reductions in some areas. About the second myth, she affirms that renewable energy for export could potentially require more long-term maintenance of infrastructure, generate more local jobs and produce more stable revenues than oil and gas have done, especially compared to oil exporters with oil and gas production located offshore and dominated by international oil companies and workers, such as Angola. The third myth claims that interstate electricity cut-offs could become an important foreign policy tool. However, the author explains that net-importer countries will still have the option of developing their own renewables potential and thus face long-term make-or-buy choices. Lastly, the author affirms that the fourth myth—cybersecurity as a geopolitical risk—is overstated sometimes. 
She points out that it is probable that increased use of renewable energy will lead to greater decentralization and this may actually make the system more resilient. In conclusion, Overland affirms that renewable energy resources are abundant but diffuse, technologies for capturing, storing and transporting them will instead become more important. International energy competition may, therefore, shift from control over physical resources and their locations and transportation routes to technology and intellectual property rights.

Gielen et al. (2019) explore the technical and economic characteristics of an accelerated energy transition to 2050, affirming that energy efficiency and renewable energy technologies are the core elements of that transition. They notice that countries around the world are in the midst of an energy transition that appears to favour electricity as the preferred final energy carrier, which is favourable from the perspective of both renewables and energy efficiency. Indeed, electricity is an efficient energy carrier and it becomes a clean source of energy when it is sourced from renewables. Their analysis shows that the decarbonization of the energy system is affordable, since the additional cumulative investments over the 2015-2050 period would be $\$ 27$ trillion, equivalent to $\$ 0.77$ trillion per year on average in the same period. Also, the energy transition would produce new jobs (around 19 million additional direct and indirect jobs in 2050) offsetting the loss of old jobs (around 7 million); therefore, the global energy transition results in 11.6 million additional direct and indirect jobs in the energy sector.

Hache (2018) aims to analyse the geopolitical consequences of the spread of renewable energies worldwide. Despite it would be tempting to conclude that the energy transition to renewables will gradually end today's geopolitics of fossil fuels, he believes that new challenges induced by energy transition policies could paradoxically turn out being as complex as today's geopolitics of energy. Local and decentralized relations could indeed add a new geopolitical layer to current traditional actors, while technical, economic, sociological, behavioural, spatial and legal dimensions could also complicate the emerging puzzle. A substantial increase of renewables into the wold's energy mix could lead to new, unexpected interdependencies such as dependencies to critical materials, a new geopolitics of patents and the implementation of renewable diplomacy.

Stratfor (2018) publishes an assessment on how renewable energy will change geopolitics. Since the increasing relevance of the renewable sources, there will be a significant geopolitical shift from the current energy geopolitical scenario. It affirms that some countries will fare better than others in the course of the transition, for instance, Germany, the US and China. Indeed, China has raced ahead to become the world's unrivalled leader in the manufacture of clean energy products, in the past decade, as well as the world's biggest miner and supplier of rare earth materials, biggest deployer of renewable energy capacity and biggest market for electric vehicles. It affirms that smaller countries such as Sweden, Denmark, Uruguay, Morocco and Kenya could gain outsize regional influence as a result of the transition, thanks to their potential for exporting renewable energy and technology. The main losers will be traditional oil exporters, such as Venezuela, Kazakhstan and the GCC states. The article argues that renewable energy probably will not have the same power to 
spark large-scale military confrontations, especially in the Middle East, inspiring increased cooperation among states by encouraging regional grid integration. However, it highlights some risks, such as cyberattacks and interruptions in supply of clean tech minerals. Finally, it affirms that trade will continue to be a source of conflict among states, for example, on intellectual property theft, dumping and domestic content requirements, undermining the global trading regime if they become heated enough.

O'Sullivan et al. (2017) provide the reader with a discussion about the shift of energy geopolitics from the one related to fossil fuels to the one of renewable energy sources. The paper discusses seven mechanisms through which renewables could shape geopolitics. First, the authors affirm that cartels could develop around materials critical to renewable energy technologies. Second, they assess that in a world in which renewables are the dominant source of energy, capital for investment and technology may increasingly become sources of international cooperation or rivalry. Conflicts might be developed over the transfer of technology between developing and developed countries as well as over renewable energy infrastructure. Third, they affirm that the prevalence of the resource curse could be affected by a rise of renewable energy, in different ways, namely: petrostates will lose access to the high rents associated with the curse; whether countries that produce large amounts of renewable energy are likely to become subject to the curse; and potential for a new resource curse in countries rich in rare earth elements. Fourth, the geopolitical complexity of greater electric interconnections between nations, which could create both more vulnerabilities for electricity importers and more interdependence, reducing risks of conflict. Five, the reduction of oil and gas consumption could lead political reform and economic diversification in the fossil fuel producers; but it might lead also to political instability. Six, renewable sources will reduce the risk of conflict and instability that climate change would otherwise generate; Africa is identified as the region where large-scale deployment of renewables may have significant geopolitical consequences. And seven, renewables could help to foster sustainable energy access, contributing to lasting solutions to instability and conflict.

Scholten and Bosman (2016) explore the potential political implications of the geographic and technical characteristics of renewable energy systems. The authors do so through a thought experiment that imagines a purely renewable-based energy system, keeping all else equal. The major implications for renewable energy base markets found by the authors are two: first, countries face a make-or-buy decision, meaning that they have a choice to produce or import energy; second, electricity is the dominant energy carrier, implying a more physically integrated infrastructure with stringent managerial requirements. They illustrate the strategic concerns arising from these implications with two scenarios: continental, following a buy decision and more centralized network; and National, following a make decision and more decentralized network. Three observations stand out compared to the geopolitics of an energy system based on fossil fuels. First, a shift in considerations from getting access to resources to strategic positioning in infrastructure management; second, a shift in strategic leverage from producers to consumers and those countries being able 
to render balancing and storage services; and third, the possibility for most countries to become a 'prosumer country' may greatly reduce any form of geopolitical concern.

Johansson (2013) explores the security aspects of future renewable energy systems, affirming that renewable energy systems can improve some aspects of security, but they will not automatically lead to the removal of all types of security problems and new problems will most certainly arise. He outlines that the approach to the energy systems as a subject generating or enhancing insecurity can be divided into three different types of risk areas: economic-political, technological and environmental. Regarding the first type of risk area (economic and political risks) he pointed the argument for assuming a reduced risk of single countries being able to exert pressure or influence on individual countries is that renewable energy sources are less concentrated and available in all countries. He affirms the renewable energy source with the greatest technological risks is probably hydropower, where dam safety is a significant issue, while about the third type (environmental risks) he declares that renewable energy will generally lead to a reduced impact in terms of climate change compared with fossil fuels as long as it is sustainably produced. In conclusions, he affirms that the main advantage of renewable energy from a long-term energy security perspective is the fact that it is based on flows instead of exhaustible stocks.

\section{Minerals and Metals for Low-Carbon Technologies}

Another relevant topic that will be analysed in the book is the minerals and metals for low-carbon technologies, which are often believed as new geopolitical leverages in the global energy transition. IISD (2018) published a report in which identifies 23 key minerals that will be critical to the development and deployment of renewable technologies, such as solar panels, wind turbines, electric vehicles and energy storage technologies. It affirms that a substantial percentage of the minerals required for green energy technologies are located in states with high measures of fragility and corruption; cobalt, graphite, copper and rare earths are of particular concern. Analysing the degree of state fragility and corruption, the report shows a picture where potential hotspots emerge, particularly in South America, sub-Saharan Africa and Southeast Asia. The report states that the increased extraction of many of the identified minerals has, in the past and at resent, been linked with local grievances, tensions and violence, in the worst cases. It examines five case studies: cobalt in the DRC, rare earths in China, Nickel in Guatemala, bauxite and alumina in guinea, lithium in Zimbabwe. Therefore, it highlights the need to ensure the responsible sourcing of the minerals required for green energy technologies and it recognizes some progress, such as strong guidance on responsible supply chains.

Also, the World Bank (2017) took into considerations, the role of minerals and metals for a low-carbon future. The report examines which metals will likely rise in demand to be able to deliver on a carbon-constrained future, particularly aluminium, cobalt, copper, iron ore, lead, lithium, nickel, manganese and rare earths. The report 
focuses on wind, solar and energy storage batteries as they are commonly recognized as key elements in delivering future energy needs at low/zero GHG emission levels. The study addresses what materials are required in the scaled-up production of these technologies and to what degree will that demand be driven by a range of the global climate scenarios. The report shows that the technologies assumed to populate the clean energy shift are in fact significantly more material intensive in their composition that current traditional fossil-fuel-based energy supply systems. It provides precise estimates on the actual demand for metals which is predicated by at least two independent variables: the extent to which the global community of nations actually succeeds in meeting its long-term Paris climate goals and the nature of intra-technology choices. Finally, the report examines how resource-rich developing countries might best position themselves to take advantage of the evolving commodities market responding to a low-carbon energy transition. The shift to low-carbon energy will produce global opportunities with respect to a number of minerals. The Latin America region (Chile, Brazil, Peru, Argentina and potentially Bolivia) is in an excellent position to supply the global energy transition. Africa, with its reserves in platinum, manganese, bauxite should also serve as a burgeoning market for these resources. With respect to Asia, the most notable finding is the global dominance China enjoys on metals, both production and reserve levels. India is dominant in iron and steel, while Indonesia has opportunities with bauxite and nickel, as does Malaysia and Philippines to a lesser extent. Lastly, the report affirms that, in Oceania, the massive reserves of nickel to be found in New Caledonia should not be overlooked.

Bazilian (2018) considers the implications of the critical role of minerals and metals in the current 'energy transition'. He affirms that the location of the critical minerals and metals shows the clear need to focus on issues around environmental, social, trade and other governance-related issues. Indeed, governance issues can have a major impact on the reliability of the supply of these materials. The author points out that the largest potential reserves exist in developing countries, which are especially dependent on the revenues from mining and this typically serves to exacerbate governance challenges.

In a study, de Ridder (2013) focuses on the geopolitics of minerals for renewable energy technologies. He pointed out that minerals are not scarce because there are not enough minerals to be found in the Earth's crust; the total availability of minerals in the earth's crust in itself is irrelevant for the geopolitics of minerals for renewable energy. Mineral supply depends on whether known mineral deposits are profitable for extraction with current or future technology and under current or future market conditions. The degree of reliance depends on what services and products countries produce and on their economies' position along the supply chain; countries that produce renewable energy technologies sit closer to the refining stage in the supply chain than other countries. He underlines the fact that the global energy transition is taking place within the transition of international system towards a multipolar world, while some state capitalist tendencies are becoming more prominent. The paper looks at how both import-dependent and mineral producing countries are responding to 
these developments and what the implications are for the balance of cooperation and conflict.

Neil and Speed (2012) published a report about the strategic implications of China's dominance of the global rare earth elements (REE) market. The authors highlight that China's de facto monopoly on rare earth mining and processing and its growing control over rare earth manufacturing enable Beijing to powerfully influence global supply. They affirm that China's near-total domination of the rare earths market is likely to continue over the near term as Beijing works to consolidate its position as the principal global REE supplier. This situation poses a threat to some military capabilities of the US and its principal allies. Nevertheless, due to this dominance, even if the US and its allies take steps to launch, subsidize and protect domestic rare earth mining, processing and manufacturing industries, such measures will take time to become productive, and are unlikely to prevent near-term shortages of these elements. Over the longer term, China's domination of the rare earths market is likely to wane as its reserves are drawn down; as new sources of supply are developed; as recycling becomes increasingly cost-effective; as new technologies replace rare earth-dependent technologies; and as the governments of the advanced, industrialized states look at alternative means to implement 'green' policies and practices.

\section{Governing the Global Energy Transition}

Goldthau et al. (2018) affirm that the energy transformation essentially implies a systemic shift; from a global perspective, the low-carbon transformation is likely to render the energy system more sustainable, but also much more heterogeneous. The energy transformation will successively reduce dependence on imports, promising a 'security dividend'. If more energy is produced locally, this as an impact on the relations between producer, transit and consumer countries. The authors explain also new risks and challenges, notably in the area of grid stability and cybersecurity. Geopolitically, the restructuring of the energy system will not threaten the major oil and gas producers as quickly and existentially as is generally assumed. A heterogeneous, fragmented energy system would neatly fit an increasingly multipolar world order underpinned by a more protectionist stance towards trade. Yet, mercantilist energy policies present the threat of spiralling rivalries between 'energy block'. Therefore, the authors affirm that this condition makes multilateral cooperation an indispensable policy goal in order to radically and rapidly restructure the energy system worldwide.

WEF (2018) assesses the effective energy transition of 114 countries' energy systems, thanks to an index, the Energy Transition Index (ETI). Through the ETI, the report highlights that over the last 5 years, more than $80 \%$ of countries improved their energy systems, but further effort is needed to resolve the world's energy-related challenges. Secondly, countries can foster progress in three ways by: establishing favourable conditions for energy system stakeholders, targeting improvement across all three triangle dimensions, and by pursuing improvement levers with synergistic 
impact across the system. Thirdly, countries follow different transition paths and need to develop country-specific roadmaps.

Goldthau (2017) explains that, in economic terms, energy assets will move further up the value chain, from commodities to technologies. The author states that there will be winners and losers: technology leaders (OECD nations and China) will benefit most, while countries lacking technology and capital, mainly in the global south, will lose out as well as countries that are rich in fossil fuels could become unable to sell oil or coal, with their economies deeply damaged. Goldthau states that to avert this, the low-carbon transition needs to be governed globally and three factors are key: credible and legitimate leadership; information about climate-related risks to guide investment and global partnerships to advance low-carbon technology. He suggests the $\mathrm{G} 20$ as the coalition of nations well placed to take the helm in this transformation. Indeed, about being a credible and legitimate leadership, the G20 includes nations that lead in technology and those that lag behind; industrialized economies; rising powers; resource-rich nations and resource-poor ones. Second, G20 could become global mechanism needed to share information about climate-related investment risk, especially through its Task Force on Climate-Related Financial Disclosures. Third, it would establish global partnerships between technology leaders and laggards to advance the take-up of low-carbon technologies.

In a paper, Andrews-Speed (2016) aims to demonstrate the benefits of applying a wider set of institutional theories to the study of the low-carbon energy transition. He draws principally on rational choice and historical institutionalism with selective reference being made to key concepts within social and organizational institutionalism as well as discursive institutionalism. The paper has sought to show that a broader institutional perspective provides useful insights into the wider context of the organizational field or socio-technical regime. In particular, it has drawn attention to how the general features of the political and economic system and of the national culture may shape the nature, pace and direction of the low-carbon energy transition.

Roehrkasten et al. (2016) publish a study about the G20 and sustainable energy within the global energy transition. The study analyses the G20's potential for advancing a global transition to sustainable energy. It comprises short studies on the energy trends and the domestic and international policy priorities of 13 G20 countriesArgentina, Brazil, China, France, Germany, India, Indonesia, Japan, Russia, Saudi Arabia, South Africa, Turkey and the US-plus the EU. Despite all of the G20 members covered in this study remain highly dependent on fossil fuels, all of them adopted the Paris Agreement. The authors state that a concerted action by G20 countries can offer an important boost to building a sustainable, low-carbon energy system. Therefore, it is essential that the G20 deepens its engagement in key areas, such as renewable energy, energy efficiency, access to energy. Global energy governance faces significant challenges, because governments have been hesitant to engage in global cooperation on energy, mainly due to sovereignty concerns. The study identifies a promising approach is that the G20 partners cooperate with other international institutions, including IEA and IRENA. The G20 can complement and add coherence to the global energy institutional landscape by entitling existing institutions to carry on its initiatives. 
Agreeing with the argument that the global energy transition could occur much faster than research on historic transitions suggests, Kern and Srogge (2016) argue that at the heart of the pace of low-carbon energy transitions is firm political commitment at all levels of governance. They highlight three main aspects-agency, international dynamics and the Paris Agreement-which make them optimistic about an acceleration of the global energy transition towards low carbon. They affirm that accelerating the decarbonization of the global energy system is by no means a straightforward exercise but requires hard political work as well as strong political commitment to fighting climate change. They argue that the Paris Agreement has ushered in a new era in which decarbonization and a focus on energy demand reduction and increasing energy efficiency will become the 'new normal', thereby leading to a new paradigm in thinking governing energy transitions.

Instead, Van de Graaf (2013) analyses fragmentation in global energy governance. He explains why the creation of additional institutions is highly unlikely according to conventional institutionalist thinking. The paper proposes an explanation for it, based on the capture of institutions by particular states or interest groups. The capture of an institution can spur the creation of a countervailing organization if there exists a sufficiently strong coalition of dissatisfied states in which the incumbent institution has lost domestic support. He argues that the push to create IRENA can be viewed partly as a symbolic action, taken for internal political reasons of some countries, and therefore challenges the strict functionalist understanding of institutions, revealing that not all institutions are created with the sole purpose of reducing transition and information costs. The author uses the case study as a reminder that international organizations are not neutral vehicles but embody certain interests and principled beliefs. He states that the creation of a specialized renewable energy agency raises the spectre of further institutional fragmentation in global energy governance along sectoral lines with each sector having its own international institution.

Goldthau (2011) lays out the main challenges that need to be addressed during the looming energy transition process. He declares that global governance arrangements need to be inclusive, commit involved actors to achieving a low-carbon future, allow for feedback mechanisms within various levels of the process and be adaptive to previously unperceived challenges along the way. In general terms, the author affirms that future research on global energy governance will need to link the still de-coupled research areas of energy security, energy access and climate change, and address them in the context of a looming energy transition. He underlines that current research bias towards the 'who?' in global energy governance needs to give way to asking more of 'what needs to be governed, and how?'.

\section{Financing the Global Energy Transition}

The last topic analysed is related to need to finance the global energy transition. Christianson et al. (2017) affirms that finance provided and catalyzed by multilateral development banks (MDBs) will help pay for implementation of the UN Sustainable 
Development Goals and the Paris Climate Agreement in many developing countries. The authors notice that it is less known about how investments across their entire energy supply portfolios relate to achieving sustainable development and climate change objectives. The report underlines that the different investment patterns seem to reflect the different mandates of the MDBs, the World Bank and ADB work mainly with public counterparts, while the IFC works with the private sector.

Hall et al. (2018) point out that up to $\$ 61$ trillion of power systems is needed to fulfil the Paris Agreement, affirming that the mobilization of so much capital is a huge challenge for the world. Indeed, it is unlikely that this kind of amount would be sourced from one form of finance alone. Therefore, it is more likely that various mixes of state, commercial and 'alternative' money capital will be required for low-carbon energy transitions. The paper uses a comparative analysis of two developed economies (Germany and UK) to explore how 'alternative' forms of finance operate in each nation's energy investment landscape. The authors find that alternative finance is often set in opposition to commercial capital. Alternative finance in both nations is motivated by financial justice outcomes that are poorly understood in current energy policy. They identify the six categories of justice most relevant to financing energy transition, which are: affordability, good governance, due process, intra-generational equity, spatial equity and financial resilience. Energy policy that seeks to mobilize capital, should take account of all six principles. The analysis shows that taking account of the variety of capitalism in each nation, and its attendant financial institutions can illuminate several ways in which these principles can be operationalized, from pursuing financial innovation through alternative platforms to expanding public or mutual banking provisions.

IRENA (2018) affirms that the landscape of renewable energy finance has evolved rapidly. Investment reached a comparable milestone in 2015, when renewable power technologies for the first time attracted more finance than non-renewable power technologies. Clearly, investment levels are highly responsive to policy changes. The East Asia-Pacific region was the dominant destination for renewable energy investment, with China as the main driver. The report outlines the significant role of the private sector; indeed, private sources provide the bulk of renewable energy investment globally-over $90 \%$ in 2016. Private investors overwhelmingly favour domestic renewable energy projects - $93 \%$ of the private portfolio in 2013-2015whereas public investment is more balanced between in-country and international financing.

Frankfurt School-UNEP Centre \& BNEF (2018) publish a report representing global trends in renewable energy investment in 2018. The report underlines that the leading location by far for renewable energy investment in 2017 was China, accounting for $\$ 126.6$ billion or $45 \%$ of the global total. This figure has been affected by the extraordinary solar boom in China in 2017. Due to policy uncertainties, renewable energy investment in the US was far below China, at $\$ 40.5$ billion. The report shows that also Europe suffered a big decline of $36 \%$ to $\$ 40.9$ billion, mainly due to a sharp decline in UK investment, due to the end to subsidies for onshore wind.

OECD/IEA \& IRENA (2017) publish a report on the perspectives for the energy transition. Their analysis finds that the energy sector transition could bring important 
co-benefits, such as less air pollution, lower fossil fuel bills for importing countries and lower household energy expenditures. The energy transition is often linked to significant amounts of money in order to achieve it. However, the report shows that while overall energy investment requirements are substantial, the incremental needs associated with the transition to a low-carbon energy sector amount to a small share of world GDP. Indeed, according to IEA, additional investment needs would not exceed $0.3 \%$ of global GDP in 2050, while according to IRENA, the additional investment required would be $0.4 \%$ of global GDP in the same year with net positive impacts on employment and economic growth.

IISD (2017) articulates how fossil fuel subsidy reform can contribute to a just transition and how this reform can be more successful under a just transition framework. Fossil fuel subsidies are a barrier to just transition and green economies because they are often socially regressive. The report identifies three core elements for a successful reform: getting the prices right; managing impacts and building supports. The report states that the scale of finance required for the transition is expected to be in the order of many billions of dollars; there is no guarantee to provide the scale or targeted supports required to foster the transition; and fossil fuel subsidies total at least $\$ 425$ billion per year, which, if removed could go a long way to financing just transition. Therefore, reforming fossil fuel subsidies will contribute to the transition to green economies by removing supports for fossil fuel sectors that harm the environment; utilizing the revenue raised from reform can go a long way to supporting the policies required for just transition.

Acknowledgments The authors would like to thank Dr. Kairat Kelimbetov, Governor of the AIFC, for his insights and for allowing us to to use some of the AIFC development strategy ideas and concepts

\section{References}

\section{Global Trends}

Goldthau A, Westphal K, Bazilian M, Bradshaw M (2019) How the energy transition will reshape geopolitics. Nature 669:29-31

Hafner M, Wochner A (2020) How tectonic shifts in global energy are affecting global governance. In Grigoriev L, Pabst A (eds.) Global governance in transformation. Springer, Berlin, pp 147-162 IRENA (2019) A new world. The geopolitics of the energy transformation. In: IRENA 


\section{Europe}

Bressand A (2012) The changed geopolitics of energy and climate and the challenge for Europe. A geopolitical and European perspective on the triuple agenda of competition, energy security and sustainability. In: Clingendael international energy programme (CIEP), CIEP paper 04

Eyl-Mazzega M-A, Mathieu C (2019) Strategic dimensions of the energy transition. Challenges and responses for France, Germany and the European Union. Institut Français des Relations Internationales, Etudes de l'IFRI, April 2019

Lombardi P, Gruenig M (eds) (2016) Low-carbon energy security from a European perspective. Academic Press

\section{United States}

Pascual C (2015) The new geopolitics of energy. Center on Global Energy Policy and School of International and Public Affairs, Columbia University, September 2015

\section{Russia}

Makarov I, Chen Y-H, Paltsev S (2017) Finding itself in the post-paris world: Russia in the new global energy landscape. MIT joint program global change, report 324, December 2017

\section{MENA}

Goldthau A, Westphal K (2019) Why the Global Energy Transition does not mean the End of the Petrostate. Global Policy, Policy Insights

Griffiths S (2017) A review and assessment of energy policy in the Middle East and North Africa region. Energy Policy 102(2017):249-269

Luomi M (2015) The international relations of the green economy in the gulf: lessons from the UAE's state-led energy transition. Oxford Institute for Energy Studies (OIES), OIES paper: MEP 12, May 2015

Luomi M (2018) The foreign relations of energy transitions - framing the issue for the UAE. Emirates Diplomatic Academy (EDA), EDA Insight, December 2018

Tagliapietra S (2019) The impact of the global energy transition on MENA oil and gas producers. Energ Strat Rev

Weatherby C, Eyler B, Burchill R (2018) UAE energy diplomacy: exporting renewable energy to the global south. Trends report, Trends Research and Advisory \& the Stimson Centre 


\section{The Impacts of the Energy Transition on Economic Growth and Income Distribution}

Cludius JM (2015) Distributional effects of energy and climate policy. PhD thesis, Doctor of Philosophy, UNSW Business School, UNSW Australia

Dercon S (2014) Is green growth good for the poor? Policy Research working papers no. 6936. World Bank, Washington DC

Grösche P, Schröder C (2014) On the redistributive effects of Germany's feed-in tariff. Empirical Economics. 46(4):1339-1383

Hallegatte S, Bangalore M, Bonzanigo L, Fay M, Kane T, Narloch U, Rozenberg J, Treguer D, Vogt-Schilb A (2016) Shock waves: managing the impacts of climate change on poverty. World Bank, Climate Change and Development, Washington DC

IRENA (2016) Renewable energy benefits: Measuring the economics. IRENA

Islam N, Winkel J (2017) Climate change and social Inequality. Working paper no. 152. UN Department of Economic \& Social Affairs (DESA)

OECD (2017) Investing in climate, investing in growth. OECD editions, Paris. https://doi.org/10. 1787/9789264273528-en

Santos Pereira D, Cardosomarques A, Fuinhas JA (2019) Are renewables affecting income distribution and increasing the risk of household poverty? Energy 170:791-803

Zachmann G, Fredriksson G, Claeys G (2018) The distribution effects of climate policies. Bruegel blueprint series, vol 28. http://bruegel.org/wp-content/uploads/2018/11/Bruegel_Blueprint_28_ final1.pdf

\section{The Global Energy Transition and the Global South}

Hirsch T, Matthess M, Fünfgelt J (2017) Guiding principles \& lessons learnt for a just energy transition in the global south. Friedrich Erbert Stiftung

\section{The Geopolitics of Renewable Energy}

Gielen D, Boshell F, Saygin D, Dbazilian M, Wagner N, Gorini R (2019) The role of renewable energy in the global energy transformation. Energ Strat Rev 24(2019):38-50

Hache E (2018) Do renewable energies improve energy security in the long run? Inter Econ 156(2018):127-135

Johansson B (2013) Security aspects of future renewable energy systems: A short overview. Energy 61(2013):598-605

O'Sullivan M, Overland I, Sandalow D (2017) The geopolitics of renewable energy. Columbia Center on Global Energy Policy \& Harvard Belfer Center for Science and International Affairs, Working paper, July 2017

Overland I (2019) The geopolitics of renewable energy: debunking four emerging myths. Energ Res Soc Sci 49(2019):37-40

Scholten D (ed) (2018) The geopolitics of renewables. Lecture Notes in Energy, vol 61. Springer, Berlin

Scholten D, Bosman R (2016) The Geopolitics of Renewables: Exploring the political implications of renewable energy systems. Technol Forecast Soc Chang 103(2016):273-283 
Stratfor (2018) How renewable energy will change geopolitics. Strat for assessments, https://worldview.stratfor.com/article/how-renewable-energy-will-change-geopolitics. Accessed 27 June

\section{Minerals and Metals for Low-Carbon Technologies}

Bazilian MD (2018) The mineral foundation of the energy transition. Extr Ind Soc 5(2018):93-97 de Ridder M (2013) The geopolitics of mineral resources for renewable energy technologies. THE HAGUE Centre for Strategic Studies, August 2013

IISD (2018) Green conflict minerals: the fuels of conflict in the transition to a low-carbon economy. IISD report, August 2018

Neill DA, Speed E (2012) The strategic implications of China's dominance of the global rare earth elements (REE) market. Defence R\&D Canada, Centre for Operational Research and Analysis, September 2012

WORLD BANK (2017) The growing role of minerals and metals for a low-carbon future, June 2017

\section{Governing the Global Energy Transition}

Andrews-Speed P (2016) Applying institutional theory to the low-carbon energy transition. Energ Res Soc Sci 13(2016):216-225

Goldthau A (2011) Governing global energy: Existing approaches and discourses. Curr Opininion Environ Sustain 3(4):213-217

Goldthau A (2017) The G20 must govern the shift to low-carbon energy. Nature 546:203-205

Goldthau A, Keim M, Westphal K (2018) The geopolitics of energy transformation: governing the shift - transformation dividends, systemic risks and new uncertainties. Stiftung Wissenschaft und Politik (SWP), SWP Comment No. 42, October 2018

Kern F, Srogge K (2016) The pace of governed energy transitions: agency, international dynamics and the global Paris agreement accelerating decarbonisation processes? Energ Res Soc Sci 22(2016): 13-17

Roehrkasten S, Thielges S, Quitzow R (2016) Sustainable energy in the G20 - prospects for a global energy transition. Institute for Advanced Sustainability Studies (IASS)Potsdam, IASS Study, December 2016

Van de Graaf T (2013) Fragmentation in global energy governance: explaining the creation of IRENA. Glob Environ Polit 13(3):14-33

WEF (2018) Fostering effective energy transition. A fact-based framework to support decisionmaking. World Economic Forum, Insight report, March 2018

\section{Financing the Global Energy Transition}

Christianson GI, Lee A, Larsen G Green A (2017) Financing the energy transition: whether World Bank, IFC, and ADB energy supply investments are supporting a low-carbon, sustainable future. World Resources Institute, Working paper, May 2017 
Frankfurt School-UNEP Centre \& BNEF (2018) Global trends in renewable energy investment 2018

Hall S, Eroelich K, Edavis M, Holstenkamp L (2018) Finance and justice in low-carbon energy transitions. Appl Energy 222(2018):772-780

IISD (2017) Fossil fuel subsidy reform and the just transition: integrating approaches for complementary outcomes. GSI report, December 2017

IRENA (2018) Global landscape of renewable energy finance. IRENA

OECD/IEA \& IRENA (2017) Perspectives for the energy transition. Investment needs for a lowcarbon energy system. IEA \& IRENA

Open Access This chapter is licensed under the terms of the Creative Commons Attribution 4.0 International License (http://creativecommons.org/licenses/by/4.0/), which permits use, sharing, adaptation, distribution and reproduction in any medium or format, as long as you give appropriate credit to the original author(s) and the source, provide a link to the Creative Commons license and indicate if changes were made.

The images or other third party material in this chapter are included in the chapter's Creative Commons license, unless indicated otherwise in a credit line to the material. If material is not included in the chapter's Creative Commons license and your intended use is not permitted by statutory regulation or exceeds the permitted use, you will need to obtain permission directly from the copyright holder.

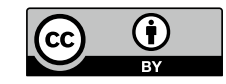

